\title{
WestVirginiaUniversity
}

THE RESEARCH REPOSITORY @ WVU

Faculty \& Staff Scholarship

$6-2020$

\section{Innovation for the Engaged Librarian}

Marian G. Armour-Gemmen

West Virginia University, marian.armour-gemmen@mail.wvu.edu

Follow this and additional works at: https://researchrepository.wvu.edu/faculty_publications

Part of the Entrepreneurial and Small Business Operations Commons, and the Information Literacy Commons

\section{Digital Commons Citation}

Armour-Gemmen, Marian G., "Innovation for the Engaged Librarian" (2020). Faculty \& Staff Scholarship. 2945.

https://researchrepository.wvu.edu/faculty_publications/2945

This Conference Proceeding is brought to you for free and open access by The Research Repository @ WVU. It has been accepted for inclusion in Faculty \& Staff Scholarship by an authorized administrator of The Research Repository @ WVU. For more information, please contact ian.harmon@mail.wvu.edu. 


\section{Innovation for the Engaged Librarian}

\section{Ms. Marian G. Armour-Gemmen, West Virginia University}

Marian Armour-Gemmen has been the Patent \& Trademark librarian at West Virginia University Libraries since 2003. In this capacity she assists inventors throughout the state of West Virginia. She is also an Engineering bibliographer. Previously she worked as the head of the Physical Sciences Library and as an associate in the Government Documents department. She is a past president of the Patent \& Trademark Resource Center Association. She received U.S. Patent 4,993,680 on February 19, 1991. She holds a M.L.I.S. from the University of South Carolina, a M.A. from the University of Michigan, and a B.A. from Calvin College. 


\title{
Innovation for the Engaged Librarian
}

\begin{abstract}
As librarians, we constantly innovate to meet the needs of our users and to utilize new technology. Discovery is an important part of this process. When we discover our patrons' pain points, we can more easily adapt to their needs. As the National Science Foundation's Innovation Corps program is implemented in more and more universities, engineering and patent librarians facilitate faculty and scientists in using the Business Model Canvas. Librarians can help faculty and scientists with familiarizing themselves with library resources to fill key parts of the Canvas. Additionally, this canvas is often implemented in innovation centers across campuses, and becoming familiar with this canvas can assist students as well. Understanding the innovation ecosystem at one's university is fundamentally important, since intellectual property plays an important role in innovation. This Business Model Canvas, as well as understanding the innovation ecosystem, can provide librarians with useful tools to engage with innovators and entrepreneurs.

Introduction

In order to stay relevant, the modern library is an ever-changing one: resources expand and withdraw, technology arises and grows dated, and visibility becomes limited as resources become more electronic and less physical. However, as these aspects of a library change, so too does the clientele that is interested in using the variety of services these modern libraries provide.

In today's library, a major issue is that of finding a user base, drawing their interest, and serving their needs in a way that is pleasant and creates repeat clients. Outreach is a major part of this issue, but even more important than that is finding resources that the clients will find userfriendly and practical.
\end{abstract}

Serving the innovation community

Howard, Zwicky, and Phillips [1] described their work with classes, library guides, and team consultations, all of which provided both engineering library information and business information. They also worked in conjunction with the business librarian to provide technical, intellectual property and business information in support of a major competition.

Similarly, the University of Utah has integrated their three libraries into the innovation space. They were involved in the concept, prototyping, product, and commercialization stages of innovation, employing medical, business, patent, and innovation librarians to provide innovators with information resources at all of these stages [2]. Different university libraries have also sought to embed themselves with the Technology Transfer Office. The University of Arizona saw its opportunity during a time of reorganization and formalized the relationship by having librarians work on individual projects involving literature search and summaries. Elliott et al. [3] pointed out that this type of work "requires persistent engagement, vision, and diplomacy." Their initiative involved at least four librarians. 
More often discussions about libraries and entrepreneurship involve business librarians' work with the entrepreneurship/start up cycle. These articles include [4], [5] and both stress the importance of working with a PTRC or a patent librarian. Additionally, work with the National Science Foundation (NSF) Innovation Corps (I-Corps) is primarily done by business librarians or health sciences librarians [2], [6]. As engineering librarians, the NSF I-Corps presents us with the opportunity for engaging with engineering faculty who may be unaware for information resources for entrepreneurship.

Discovering our users' pain points

It is important to identify what services you would like to provide to your users, identify which users you are targeting, and communicate which services are available. To identify users, an engaged librarian needs to look beyond their obvious clientele (Engineering Departments) and explore other university initiatives that they can serve. If the university has drawn up a map of the entrepreneurial ecosystem, that can assist the librarian. Otherwise, looking at other universities' ecosystems can be useful. At West Virginia University, an ecosystem was drawn up after a one and a half year discussion with major players. It included three pathways for innovators: Student, Faculty/Staff, and State Residents. (The library is involved with all three pathways because it is not only a Patent \& Trademark Resource Center, but it also subscribes to major business databases.) The ecosystem also identifies areas of possible engagement including the LaunchLab, the prototyping labs, the Technology Transfer Office, the Entrepreneurship and Innovation Law Clinic, the new business incubator, the Statewide Business Plan Competition, the I-Corps program, and other initiatives. Speaking to the leaders of each program is imperative so that they know that they can turn to the libraries for assistance. Additionally, sending out emails regarding workshops, Federal Register notices, and database announcements can raise your visibility as well. Attending programs that are sponsored by the various programs such as pitch contests, senior design presentations, identifying classes for lectures, and participating in other programs such I-Corps, where engineers and scientists are first deciding about starting a business based on their technology, are also helpful steps to take. 


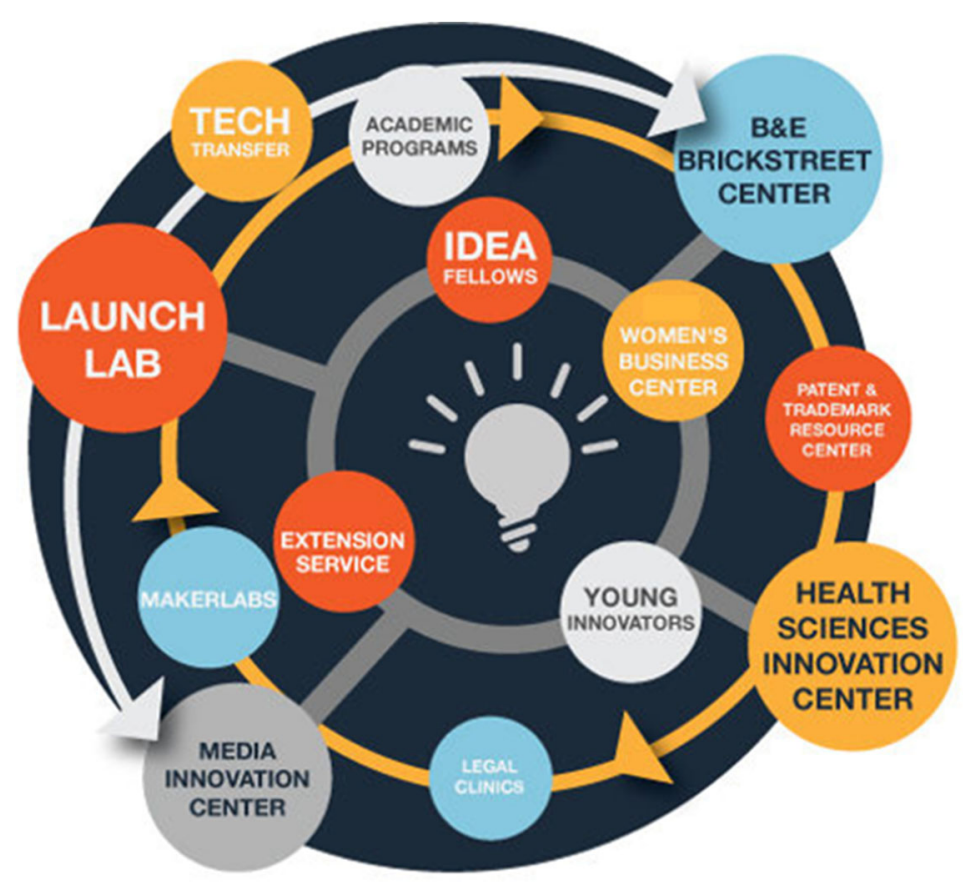

Figure 1. West Virginia University Innovation and Entrepreneur Ecosystem.

\section{NSF Innovation-Corps}

The National Science Foundation created the Innovation Corps (NSF I-Corps) in order to assist researchers and scientists with NSF grants to bring their innovations to market. Many innovations could assist people in society but lie hidden behind the doors of labs and layers of academia. This program, created in 2011, helps academics monetize their discoveries and innovations and launch them to the public. The I-Corps system utilizes Steven Blank's Lean Launchpad (see Four Steps to an Epiphany [7]). Lean Launchpad is a system employing the Business Model Canvas (BMC). The BMC, developed by Osterwalder and Pigneur [8], utilizes a customer development model, and attempts to apply the scientific method to business plans. This BMC enables a potential start-up business to envision different aspects of their start-up. It allows them to map out and potentially change their course of action ("pivot"). Faculty and graduate students propose and test business hypotheses within the space of just a few weeks. They must identify potential customers and interview them in order to refine their product or service and validate whether they have created a repeatable and saleable business model. HuangSaad et al. [9] point out that inventors know their discovery the best and therefore are best suited to establish the technical viability. The most motivated inventors will be able to work within an intensive educational experience that will expose them to language and the process of entrepreneurship. The most important aspect of this training is discovering the hypothesis for the product or service, identifying potential clients, and testing the hypothesis with them.

At West Virginia University, there have been five cohorts of the short course over the span of two years. The short course lasts three weeks and qualifies a researcher for the national course which lasts significantly longer. The teams at this university are split between engineering and health sciences, with an occasional other team. During this process, while using the BMC, the researchers must identify customer segments, value propositions, and value oppositions. 
Occasionally they will identify key resources as well. By focusing on the value propositions and the customer segments, the innovators change their perspective from developer to consumer. This process allows the scientist to still use the scientific method by formulating an hypothesis, but asks them to speak to potential consumers to find out if the problem they have is the same as what the scientist is postulating. Scientists find people to interview in their targeted consumer segments and interview them without revealing their technology.

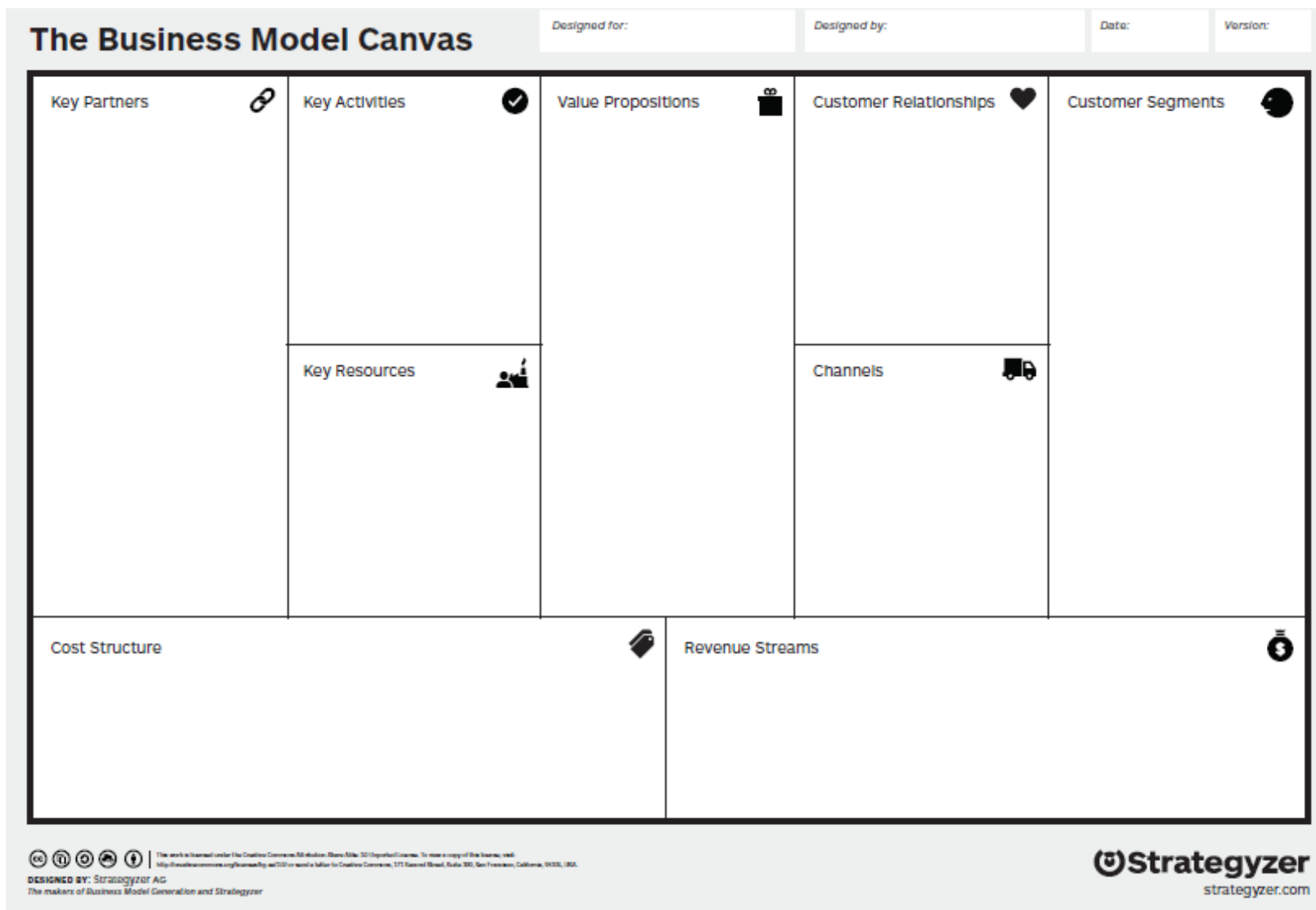

Figure 2. Business Model Canvas. Available: strategyzer.com

Figure 1 lays out nine building blocks, to assist lean startups in organizing information for their potential business: Key Partners; Key Activities; Key Resources; Value Propositions; Customer Relationships; Channels; Customer Segments; Cost Structure; Revenue Streams. These basic building blocks cover infrastructure, offering and customers, and finances. The analysis begins in the middle, with the Value Proposition, and then moves to the far right to Customer Segments. The Value Proposition is a product hypothesis, hypothesizing what the product will need to be to meet a customer need. (For more explanation of the building blocks see [8], [9].) The building block that librarians can best assist researchers with is the Value Proposition: often a researcher needs to investigate the market for their product in comparison to existing products on the market. Products such as IBIS World, Mergent Intellect, Statista, and Economic Census Industry Snapshots can be useful to identify the current market and demonstrate a product's value to its researcher. Another building block that librarians can assist with is the Customer Segment; 
business information tools such as Reference USA, PrivCo, and Mergent Intellect can assist here. Although researchers in I-Corps often know who they are targeting, sometimes they need to identify key players in different businesses and industries. Although engineering librarians in the past have emphasized specialized engineering databases for their users, with the prospect of launching new businesses, engineering librarians may need to turn to new business resources to assist their patrons.

The third building block that librarians can assist with is Key Resources. One key resource could be intellectual property. If the researcher needs to search prior art for patents or search for existing trademarks, the librarian could assist them. The I-Corps Short Course primarily emphasizes Value Propositions and Customer Segments, but inventors often have a name for a product or an invention. By offering assistance with trademarks and prior art searching, the librarian may assist the researcher before they get too familiar with their mark.

A newly created constituency (the I-Corps program on campus) creates an opportunity for the engaged librarian. A goal for Librarians is to get resources to the people who need them. This librarian saw the introduction of an I-Corps node at this university and recognized that the researchers in the I-Corps program might need to utilize library resources in order to fully succeed in their goals. Namely, business and intellectual property search resources would be very necessary to this type of work.

As a form of engagement, this librarian, after speaking with the organizer, embedded herself into the first I-Corps cohort. I was introduced by the instructor so that when people would have questions about their value propositions, customer segments, or key resources, they could ask me. I also sent out an email to participants, and the university business librarian created entrepreneurship Libguide. This Spring 2020, I completed working with four campus I-Corps cohorts and provided reference assistance in each of the aforementioned three building blocks. Two of the participants have gone on to the national competition, and resources that the libraries have provided have assisted them in making substantial and effective proposals. One of the national cohort groups is currently working on forming a company and securing funding for their business. As they have recently graduated from this university, they were able to obtain a position in the new university incubator.

\section{Conclusion}

Engagement means that librarians should pay attention to the changing landscape of the university, figure out how to fit into it, and bring library resources to the newly formed or reformed constituencies. The NSF I-Corps allows engineering librarians to be more visible to innovators and gives librarians an opportunity to introduce business resources to engineers who might otherwise be unaware of them. By embedding into a I-Corps Short Course, the engineering librarian can get in on the ground level with engineers' business development. This involvement serves as a model for other new campus initiatives. By seeking out new opportunities in innovation, librarians can continue to be engaged with their constituency and prove their relevancy, not only to researchers, but also technology transfer and university research administrators. 
References

[1] H.A. Howard, D. Zwicky, M. Phillips, “Academic Libraries Support Cross-Disciplinary Innovation and Entrepreneurship," Libraries Faculty and Staff Scholarship and Research, Paper 206, 2018. [Online]. Available: https://docs.lib.purdue.edu/lib fsdocs/206 [Accessed February 15 ,2019].

[2] J.P. Shipman and B.A. Ulmer, ed. Information and Innovation. A Natural Combination for Health Sciences Libraries. Lanham, Boulder, New York: Rowman \& Littlefield, 2017.

[3] C. Elliott, J. Dewland, J.R. Martin, S. Kramer, and J.J. Jackson Sr., "Collaborate and Innovate: The impact of academic librarians on the commercialization of university technology," Journal of Library Administration, vol. 57, no. 1, p. 36-48, 2017. [Online]. Available: https://doi.org/10.1080/01930826.2016.1215674 [June 28, 2018].

[4] J. Hoppenfeld and E. Malafi, "Engaging with entrepreneurs in academic and public libraries," Reference Services Review, vol. 43, issue 3, p. 379-399, 2015. [Online]. Available: https://doi.org/10.1108/RSR-02-2015-0011 [Accessed February 6, 2019].

[5] C. Cole and L. Lysiak, "Due diligence: Recognizing the role of patent research in the startup life cycle," Journal of Business \& Finance Librarianship, vol. 22, no. 3-4, p. 222-230, 2017. [Online]. Available: https://doi.org/10.1080/08963568.2017.1372014 [Accessed: February 6, 2019].

[6] F. Sayre, C. Lilyard, and M. Schoenborn, "For fun and profit: Supporting research commercialization with interdisciplinary liaison teams," At the Helm: Leading transformation, ACRL Proceedings, p. 236-246, 2017. [Online]. Available: http://hdl.handle.net/11299/195001 [Accessed: June 28, 2018].

[7] S.G. Blank. The four steps to the epiphany. Successful strategies for products that win, 3rd edition. San Francisco: n.p., 2007.

[8] A. Osterwalder, A. and Y. Pigneur. Business Model Generation: a handbook for visionaries, game changers, and challengers. Hoboken, New Jersey: Wiley, 2010.

[9] A. Huang-Saad, J. Fay, and L. Sheridan. "Closing the divide: accelerating technology commercialization by catalyzing the university entrepreneurial ecosystem with ICorps ${ }^{\mathrm{TM}}$," Journal of Technology Transfer, vol. 42, p. 1466-1486, 2017. [Online]. Available: Springer Complete Journals, link.springer.com [Accessed: September 28, 2018]. 